\title{
What technology for efficient support of sustainable development?
}

\author{
Eunika Mercier-Laurent \\ University Jean Moulin, Lyon 3 \\ Lyon, France \\ eunika.mercier-larent@univ-lyon3.fr
}

\begin{abstract}
Sustainable development is among the greatest challenges of this century. Sustainability and development are apparently opposite. The traditional approaches try to manage the planet protection without taking the best from technology while eco-innovation focus mainly on smart transportation, smart use of energy and water and waste recycling. Many new concepts such as Smart, Intelligent, Green or Wise City were invented to promote ... old technology. All these initiatives use data bases and machine to machine communication. The AI approaches and techniques may be very useful not only for process optimization but also for simulation before doing and education of new behaviors. This talk will present the principal advantages of using AI for balancing planet protection and technological progress.
\end{abstract}

Index Terms - Sustainable develoment, Intelligent technology, e-co-innovation, knowledge.

\section{INTRODUCTION}

$\mathrm{T}$ ECHNOLOGICAL progress is considered as a powerful engine of economy but, despite partial recycling, it generates a lot of waste and contributes to climatic changes. Computers and smartphones are quickly out of date; new software versions are available only on new devices. Most of these devices are not eco-designed.

The quickly growing population of the cities represents a lot to feed it is also a huge global market facilitated by communication technology, e-business, and transportation means. Google business model based on advertisements generates intellectual and visual pollution and is an important theft of time - time to find how to close the advertisement window or 30 seconds if this facility is not provided. The mass media promotes the "to have more and to show" mentality, through advertisements and various entertainment programs. "Buy more, throw away and buy new" are the engines of today business. Opening to business and quick development of China and other Asian and South American countries offering the low labor cost increases the relocation-out from origin countries, mainly US and Europe, in search of quick business - in aim to offer more for less and increase the firms' income. This way of doing increases also pollution in developing countries and the unemployment in Europe and other developed countries. Besides, we have to recycle products, often of poor quality, made somewhere else and travelling around the world by ships and airplanes.

Innovation is among contributors to planet disaster, because the inventors and designers think about functionality, shape, look and attractiveness and not about the overall behavior inside the environment. Business people want to sell more; nowadays a global market is addressed without thinking about the right values and right benefits.

The eco-innovation movement claims to generate new businesses and jobs but the use of technology in the related activities is moderate. Corporate Social Responsibility aims to balance environmental, economic and social impacts with a little use of traditional technology. Based mainly on norms, it aims in having an impact on products design via Product Lifecycle Management (PLM) software. Intelligent technology has a significant role to play in balancing all these components. A condition however is a capacity of different thinking and managing all available knowledge and experience that apply.

After describing main trends some perspective will be given on another way of doing and the role of intelligent technology in the transformation of society.

\section{FROM SUSTAINABILITY TO SUSTAINABLE DEVELOPMENT}

In biological systems sustainability means long life. Systems components influence each other and the balance of the whole system is the condition to survive. Human activities have affected the balance of natural ecosystems $[4,5,6]$.

Sustainable development is a principle that many people claim to have invented. The definition of the European Union is following:

"Sustainable Development stands for meeting the needs of present generations without jeopardizing the ability of futures generations to meet their own needs - in other words, a better quality of life for everyone, now and for generations to come. It offers a vision of progress that integrates immediate and longer-term objectives, local and global action, and regards social, economic and environmental issues as inseparable and interdependent components of human progress."

"Sustainable development will not be brought about by policies only: it must be taken up by society at large as a principle guiding the many choices each citizen makes every day, as well as the big political and economic decisions that have to be taken. This requires profound changes in thinking, in economic and social structures and in consumption and production patterns"'[2].

Sustainable development can be seen as a process for meeting human development goals while maintaining the ability of natural systems to provide the required natural resources and ecosystem services upon which the current 
economy and society depend. The greedy economic system is not compatible with sustainable development. In this context sustainable development is oxymora - it is impossible to be sustainable without deep understanding of our natural ecosystems (multidisciplinary knowledge) and without radical change of behaviours, objectives, values, political and economic system. Sustainable development is an attitude to learn and cultivate.

Various actions aiming in changing the way of acting and doing things are engaged, mainly by individuals and organizations. Many of them are supported by social networks and have potential to influence behaviours. For example, Uber platform (and some others) connects people offering services with those who need them. It is quick and effective, but out of the current economic practices (taxes, companies...) and raise conflicts between "old" and "new". Serious games try to push people to act [7].

Introducing the environmental principles into a design of products and services is a step forward. However the traditional PLM tools should evolve to take into consideration a new way of doing [8] by using simulators and optimizers. Technology is able to provide a considerable help, but the way of thinking should evolve to global, holistic and system [9]. For example, aeronautic and automotive industries focus on lightening weight and reducing carbon footprint, while other aspects can also be considered.

Corporate Social Responsibility requires the integration of environmental aspects into design. While it constraints companies to take care about social and environmental impact, they should also focus on economic performance. Environmental norms (ISO 26000) are very heavy; it is impossible for a small company to check and respect all these norms without loosing business. The intelligent technology can help checking and optimizing things; such systems are prototyped [12].

To remain sustainable, development requires the intensive use of available knowledge - individual and collective, from related domains, from the past and currently gained from experience.

\section{From ECO-INNOVATION TO E-CO-INNOVATION}

According to European Union [3] there are many fields and activities concerned, such as air, chemicals, green public procurement, industry, marine and coast, biodiversity, noise, soil, urban development, waste and water. The areas that should be greened are agriculture, employment, energy, fisheries, research, trade, transport...All are potential source of growth and job creation. But in existing system and with current goals, attitudes and practices, it can not work as expected. The greedy economic system aims in producing and selling more. The industrial giants impose their products and absorb competitors.

Circular economy is promoted by some wise economists and recently by European Union: "This means re-using, repairing, refurbishing and recycling existing materials and products. What used to be regarded as 'waste' can be turned into a resource. The aim is to look beyond waste and to close the loop of the circular economy. All resources need to be managed more efficiently throughout their life cycle" [16]. How they face the current practices of planned and perceived obsolescence [17]?
Circular economy is just new business concept, but nothing new - it has been practice in Poland in the 1950s and it is still practiced in poor countries. Despite generating activities, recycling uses the energy and generates pollution in many cases. Repairing involves education of new know how and another design, that should be encouraged - those of modular and reparable and reusable products (back to the 1950). AI approaches and techniques are very well suites to do that.

Another approach, connecting the best from technology and the best human capacity is those of e-co-innovation, considering all components, see Figure 1.

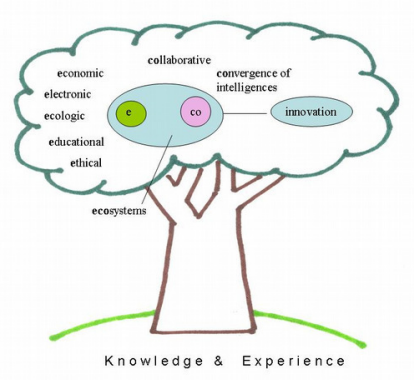

Fig. 1. e-co-innovation principles [9]

E-co-innovation is based on past and present knowledge as well as on a vision for the future. Its facets are ecological, economic, educational, electronic and ethical. It is collaborative and enables a convergence of intelligences. Inspired by nature, respecting natural and digital ecosystems it is centered on humans; such dynamics will certainly contribute to avoiding unbalance and a loss of competitiveness leading to economic, ecological and social decline.

\section{CONTRIBUTION OF AI - EXAMPLE OF WISE CITY}

The recent trends of Smart City, Intelligent City, Green and recently Wise City aim in providing services to citizens of becoming bigger and bigger cities. Actually, the population of cities is growing for different reasons, among them job offer, access to services, culture, immigration...This kind of initiatives is based on linear approximation that in $205070 \%$ of world population will be living in the Megapoles. The other factor is the ambition of politics to grow their territory. As consequence regional economy collapses in many cases and should be reinvented using local talents and resources.

The concept of Smart City was probably born in early 2000s. In aim to reboost their existing technology IBM changed in 2010 a slogan to Smarter Planet. Cisco as network provider is also involved. Intelligent City tries to be different and defines integrated model of intelligent economy, transportation, environment, governance and services for citizens [13]. The city of Nice (French Riviera) runs annually a conference on Innovative City [14]. Growing cities want to offer well being to citizens by initiating Green City which main interest is in architecture, gardening and social cohesion [15].

Among the lastest trends the Wise City of Hong Kong brings together large companies: Schneider Electric, Alstom, Veolia, Thales and KPMG, no room for small ones. KPMG claim to be integrator of all offers. They focus on improvement of living conditions: pollution, access to clean water, waste 
treatment...Hong Kong with over 7 million of habitants produces 15,000 tones of waste daily and uses $60 \%$ more water than New York. Buildings are heavy consumers and air pollution is $53 \%$ local.

The Figure 2 gives some details on main project components which are: smart energy, smart mobility, smart water, smart public services, smart buildings, smart data centers and smart integration. Public services offer seems very poor. We can notice that the offers for energy and water are a part of smart buildings. Data Center is certainly related to city management and we hope there is only one for all applications proposed by partners.

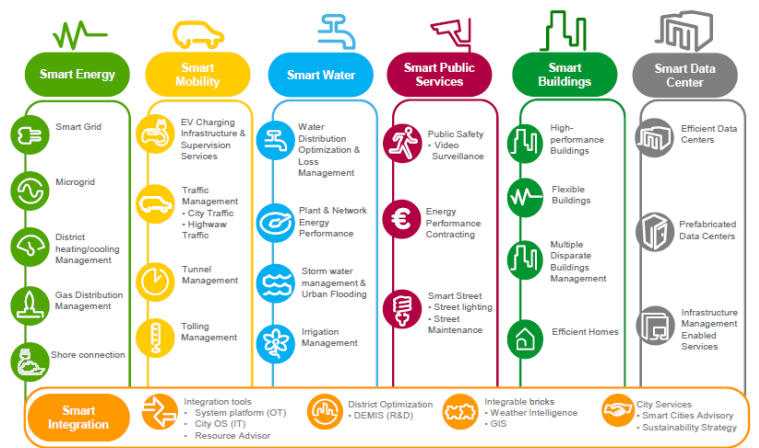

Fig. 2. Principal components of Wise City (source Schneider Electric, 2012)

Waste processing is not shown in this figure, because it is managed by another company. Such a separation generates more business for each company. They do not try to build an optimal (and cheaper) solution for the city in function of their needs; they just adapt their respective offers. The analysis of current situation and real needs is not published.

\section{A. What could be done}

The Digital Agenda for Europe [15] points out the links between domains: "Information and Communication Technologies (ICTs) enable us to see the connections between seemingly disparate issues, like transport and energy or health and economic growth, and help us find comprehensive solutions, for example in the European Innovation Partnerships on Smart Cities and Communities and on Active and Healthy ageing" [15]. Such thinking is vital for building integrated and reusable solutions.

"Sensors and embedded software make objects increasingly interactive. Computer simulation makes a direct contribution to sustainability issues, particularly with regard to environmental protection, the scarcity of raw materials, and the emergence of a low-carbon economy. Smart city ambition is offering their inhabitants increased comfort, employment and economic development."

Since over 50 years now Artificial Intelligence developed methods and techniques that are now embedded in many decision support systems, diagnostic and simulation tools, educational software, innovative electronic commerce, data, text and image mining tools, creativity "amplifiers", robots and drones.

Combination of Knowledge Management method and Artificial Intelligence techniques are available to guide and enhance the architecture of an adapted, innovative and reusable system for city management. The comprehension and common discovery of needs may help innovating the both city and in- volved companies. Implication of local people (citizens and companies), sharing their talents, knowledge and experience may be beneficial for all. Knowledge base of experience of smart cities around the word will avoid the waste on energy and money for developing again and again the similar and not connected data bases.

New attitudes can be influenced via peaceful and knowledgeable games such as intelligent purchase for less waste, reusing the packaging, intelligent use of water and energy, avoiding or combining the transportations and other are a part of fun learning for all. Behind there is strategy, problem solving, thinking and multisystem agents.

While robots were conceived to copy human intelligence there are some useful robots designed to help human as industrial or surgery robots, those able to diagnostic and fix complex equipments in places difficult or dangerous to access, such as control and monitoring cabinets, nuclear power plants or high voltage stations.

Despite of available technology for distance meetings the number of people travelling is still growing. Optimization techniques such as constraint programming are helpful for optimizing travel. However air transportation companies have their own hub and an intelligent optimizer of travels is still missing. The available "optimizers" such as kayak, sky scanner and others works for their clients and not for travelers.

Smart cities open their data and wish to make business on it. Data is as raw materials, but intelligent access to relevant information allows the large-scale dissemination, analysis and use of data for the benefit of consumers and citizens. Analytics are mainly used to find information in large amount of data. The AI techniques of knowledge discovery, such as neural networks, genetic algorithms, induction or other multi-strategy machine learning hybrid tools are available but underused.

Offering the targeted services, corresponding to the real user's needs could be a great value. The effective matching of offer and demand in many domains saves our time and help in capturing opportunities. Smartphones and future devices embedded with machine learning techniques shall learn from realtime interaction with the user and not from navigation (too many errors) or published profile only.

\section{CONCLUSION AND FUTURE WORK}

Only few examples of what can be done on city level were presented here. The main rule is to apply suitable knowledge management approach, involve the end users from the beginning and use the best adapted techniques. The principle of modularity, reusability and genericity is still valuable for defining and building an effective and replicable system that really support city management and offer expected services to citizens, organizations and companies being a part of the city (holistic approach).

The evaluation of the impact of city activities may lead to right metrics for measuring progress and leadership. However the balance between the use of technology and human capacity should be preserved. Technology producers have tendency to produce software and devices that think instead of the human and take decisions for him/her. This kind of applications may replace human at the long run and reduce his cognitive capacity. That's why we have to produce the applications that enhance human intelligence without switching it off. 
The future work is about evaluating 6D impact (technological, environmental, economic, social, cultural and cognitive) of technology.

\section{REFERENCES}

[1] G. H. Brundtland "Our Common Future", United Nations, March 1987

[2] EU - sustainable development http://ec.europa.eu/environment

[3] EU eco-innovation http://ec.europa.eu/environment/ecoap/about-ecoinnovation/index_en.htm

[4] C. Folke, C.S. Holling, C. Perrings "Biological diversity, Ecosystems and the Human Scale", Ecological applications 6(4), pp 1018-1024, Ecplogical society of America, 1996

[5] A. Lenkowa "Oskalpowana ziemia", Omega, Wiedza Powszechna, Warszawa, 1969

[6] E. Mercier-Laurent "The Innovation Biosphere. Planet and Brains in Digital Era, Wiley, ISBN.

[7] Water footprint, http://www.empreinteh2o.com/
[8] E. Mercier "Innovation Ecosystems: Example of Eco-design Process, KAM \& AI4KM, Fedscis 2013, Krakow

[9] E. Mercier-Laurent "Innovation Ecosystems", Wiley, ISBN.

[10] United Nations https://sustainabledevelopment.un.org

[11] http://wisecity.hk/

[12] Z. Feng, M.Rio, R. Allais, P.Zwolinski, T. Reyes, L. Roucoules, E. Mercier-Laurent, N. Buclet "Toward a Systemic Navigation Framework to Integrate Sustainable Development into the Company", Journal of Cleaner Production, Volume 54, pp 199-214,1 September 2013.

[13] Ville Intelligente http://www.smartgrids-cre.fr

[14] Innovative City http://www.innovative-city.com

[15] "ICT for Societal Challenges. Digital Agenda for Europe", Publication Office of the European Union, Luxemburg, 2013

[16] Circular Economy http://ec.europa.eu/environment/circular-economy/

[17] Planned Obsolescence and Perceived Obsolescence - https://www. youtube.com/watch? $\mathrm{v}=\mathrm{N} 2 \mathrm{KLyYKJGk0}$ 